\title{
Online Simulators for the Teaching of the Law of Conservation of Matter and Chemical Reactions in High School
}

\author{
Adolfo V. Obaya1*, Yvonne Rodríguez Barocio², Yolanda Marina Vargas Rodríguez ${ }^{1}$ \\ ${ }^{1}$ Department of Chemical Sciences, FES-Cuautitlan UNAM, Physical Chemistry MADEMS (Chemistry), Mexico, ${ }^{2}$ Department of Chemistry, Instituto \\ Víctor Frankl Campus Tepalcapa Edo, de Mexico, Mexico
}

*Corresponding Author: obaya@unam.mx

\section{ABSTRACT}

It is imperative that a profound transformation be carried out in the traditional way in which we teach science subjects, so it is necessary that the role of student change from being a mere recipient of information to being the main player in the construction of his knowledge. One of the strategies to achieve this is to make use of ICT, within which are educational simulators, as a support resource to facilitate the teaching-learning processes taught in the classroom. The didactic strategy developed in this work was carried out with the PhET (https://phet.colorado.edu) simulator was used to improve the teaching of the Law of Conservation of the Matter and its relationship with chemical reactions. To evaluate the learning acquired by students, the Hake factor was determined. In terms of the implementation of this didactic strategy, students demonstrated greater recognition, understanding, and appropriation of the knowledge gained about the importance of this law in chemical reactions. This teaching strategy is useful for higher middle-level schools that do not have a school science lab.

KEY WORDS: didactic strategy; ICT; educational simulator; conservation of matter; chemical reaction

\section{INTRODUCTION}

\section{Law on the Conservation of Matter}

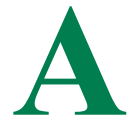
ntoine Lavoisier discovered that the total mass of all substances present after a chemical reaction is equal to the total mass before the reaction. This observation, known as the "Law on the Conservation of Matter" (Chang, 2010), which is one of the fundamental laws of chemical change and states, "Matter is not created or destroyed only is transformed." In a chemical reaction the sum of the mass of the reagents is equal to the sum of the mass of the products.

$$
\begin{gathered}
2 \mathrm{Na}_{(\mathrm{s})}+2 \mathrm{H}_{2} \mathrm{O}_{(\mathrm{l})} \rightarrow 2 \mathrm{NaOH}_{(a c)}+\mathrm{H}_{(\mathrm{g})} \\
46 \mathrm{~g} \mathrm{Na} 36 \mathrm{~g} \mathrm{H} \mathrm{H}_{2} \mathrm{O} 80 \mathrm{~g} \mathrm{NaOH} 2 \mathrm{~g} \mathrm{H}_{2} \\
46 \mathrm{~g}+36 \mathrm{~g} \quad 80 \mathrm{~g}+2 \mathrm{~g} \\
m_{\text {reactives }}=82 \mathrm{~g} \quad m_{\text {products }}=82 \mathrm{~g}
\end{gathered}
$$

Chemical Reactiown, Chemical Equation, and its Relationship to the Law of the Conservation of Matter

A chemical reaction is the process in which substances are joined together to transform into different ones. This is a symbolic representation that uses chemical formulas to describe the relative identities and quantities of reagents and products involved in a chemical reaction.

To represent what happens in a chemical reaction through an equation, it must comply with the Law on the Conservation of Matter. It should indicate that the number of atoms of reagents and products is the same on both sides of the bond.
Types of Chemical Reactions (Brown et al., 1998)

\section{Synthesis or combination reactions}

They are carried out when two or more pure substances (elements and/or compounds) react to produce a new pure substance (always a compound). Its general equation is:

$$
A+B \rightarrow A B
$$

\section{Decomposition reactions}

In this type of reaction, a compound is broken down into simpler pure substances that can be elements and/or compounds. Its general equation is:

$$
A B \rightarrow A+B
$$

\section{Simple displacement reactions}

The reaction is performed when one element moves another in a compound producing a new compound and displaced element. Its general equations are:

$$
\begin{aligned}
& A+B C \rightarrow B+A C \\
& A+B C \rightarrow C+A B
\end{aligned}
$$

\section{Double displacement reactions}

Two compounds participate in this type of reactions, in which the cation of one compound is exchanged with the cation of another compound. It can also be said that the two cations exchange anions. Its general equation is:

$$
A X+B Z \rightarrow A Z+B X
$$




\section{Symbol Recognition in the Representation of a Chemical Equation}

To represent a chemical reaction, symbols are used that constitute what we know as a chemical equation:

$$
\mathrm{CH}_{4(g)}+2 \mathrm{O}_{2(\mathrm{~g})} \rightarrow \mathrm{CO}_{2(\mathrm{~g})}+2 \mathrm{H}_{2} \mathrm{O}_{(\mathrm{l})}
$$

Substances written to the left of the arrow are called reagents and are the first member of the reaction. The substances written to the right of the arrow are the products and form the second member of the reaction. Within the structure of the chemical equation is diverse symbology that is important to know:

\section{Balancing Chemical Equations}

The balancing chemical reactions are only a consequence of the law of conservation of matter, so the mass of the reagents must be equal to the mass of the products. To balance a chemical equation, we first must identify the type to which is belongs (see Figure 1). Chemical reactions can be generally classified as acid-base or oxide-reduction:

1. In acid-base reactions no species changes their oxidation state

2. In oxide-reduction reactions, at least two species change oxidation state:

When a species loses electrons its oxidation number increases. This process is known as oxidation.

$$
\mathrm{Fe}^{2+} \rightarrow \mathrm{Fe}^{3+}+e
$$

When a species gains electrons its oxidation number decreases. This process is known as reduction.

$$
\mathrm{Mn}^{4+}+2 e \rightarrow \mathrm{Mn}^{2+}
$$

There cannot be an oxidation reaction without any reaction occurring because electrons are transferred from the oxidizing species to which it is reduced. The species that is reduced (gain electrons), is called the oxidizing agent. Similarly, the species that oxidizes (loses electrons) is called the reducing agent (Chang, 2010).

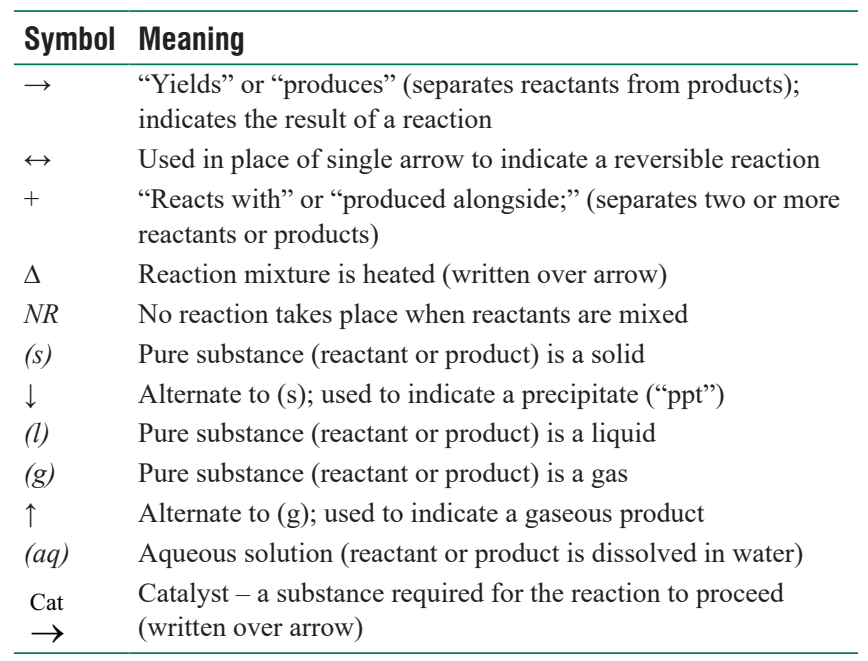

Figure 1: Symbology in the representation of a chemical equation. http:// chemistrybatz.weebly.com/11-chemical-reactions.html
Balancing means finding the stoichiometric coefficients in a reaction such that the number of atoms present (see Figure 2) in the reagents is equal to those present in the products:

$$
\mathrm{Fe}_{2} \mathrm{O}_{3}+\mathrm{C} \rightarrow \mathrm{Fe}+\mathrm{CO} \text { balanced like: } \mathrm{Fe}_{2} \mathrm{O}_{3}+3 \mathrm{C} \rightarrow 2 \mathrm{Fe}+3 \mathrm{CO}
$$

If the number of atoms present before and after the reaction is the same, then the sum of the mass of the reagents is equal to the sum of the mass of the products.

\section{TEACHING SCIENCE IN THE $21^{\text {ST }}$ CENTURY}

Rich countries with enormous economic, infrastructure, and technology resources for teaching fail to arouse their students' interest in sciences; especially in the chemistry (Galagovsky, 2007).

ICT has become more common in education, generating innovative teaching methods (Webb, 2005) that adapt to new pedagogical models, setting aside traditional teaching methods based on mere knowledge transmission. With this the role of the student has also been modified (Chiu and Wu, 2009), since they will no longer be a mere passive recipient of content but must be able to obtain the information, analyze it, and apply it in contextual situations.

Among these technological tools are educational simulators, as a support resource for teaching-learning processes that are carried out in various educational contexts (Mistler-Jackson and Buttler-Songer, 2000). The simulators allow the formation of concepts, knowledge building, and the application of these to new contexts (Mumtaz, 2000), which, for various reasons, the student cannot access from the methodological context where his learning takes place (Giammatteo and Obaya, 2018).

There are schools that do not have a school laboratory of Chemistry, which allows students to contextualize previously reviewed knowledge in class and in order to improve the teaching process (Webb and Cox, 2004) of the law of conservation of the subject and its relationship in chemical reactions, a didactic strategy was developed that uses as a learning tool the use of PhET simulators (https://phet. colorado.edu). This simulator has a collection of more than 150 interactive simulations that support the generation of significant learning about science and mathematics at all academic levels. It was created in 2002 by Carl Weiman, winner of a Nobel Prize in Physics, who thought of interactive simulations as a tool with the potential to really impact and

\begin{tabular}{|c|c|c|}
\hline \multicolumn{3}{|c|}{ Before balance } \\
\hline Reactive & Atoms & Products \\
\hline 2 & $\mathrm{Fe}$ & 1 \\
\hline 1 & $\mathrm{C}$ & 1 \\
\hline 3 & $\mathrm{O}$ & 1 \\
\hline
\end{tabular}
improve the education of the future by providing us with a tool that allows us to change the traditional learning environment to autonomous and self-taught learning, where the student is now

\begin{tabular}{llc}
\hline \multicolumn{3}{l}{ After balance } \\
\hline Reactive & Atoms & Products \\
\hline 2 & $\mathrm{Fe}$ & 2 \\
3 & $\mathrm{C}$ & 3 \\
3 & $\mathrm{O}$ & 3 \\
\hline
\end{tabular}

Figure 2: Balance chemical equations 
the main player in building their knowledge. Learning guides were also developed as a means of guiding the student through this process, thus significantly improving the understanding of this topic by allowing students to understand the importance of this law in chemical reactions and at the same time a way of motivating students' interest in science.

\section{METHODOLOGY}

A didactic sequence was designed (Perez-Rivero et al., 2019; Hernández et al., 2020) with the use of simulators for the theme Law of Conservation of Matter and its relationship to Chemical Reactions in Higher Middle Education. The didactic sequence was applied at the High School Instituto Víctor Frankl campus Tepalcapa located in the municipality of Cuautitlán Izcalli, State of Mexico, with students of the morning shift of the first semester. The group consists of 30 students between the ages of 15 and 18 years of medium-low socioeconomic stratum and in most cases from dysfunctional families with a history of addiction, has variable assistance because $35 \%$ of them work and in some cases, there are learning problems ranging from cognitive to one generated by an addiction.

This campus does not have a school laboratory, which is why PhET simulators were used, which could be used directly on the Web or downloaded. For the purposes of this work, the second option was chosen as the practices would be carried out in the computer room to avoid any kind of distraction that students might have by having the possibility to access other applications that the Web can offer them.

The type of work was quantitative in that a series of data obtained from the application of an evaluation instrument that was used as a pretest and post-test (Appendix 1) were collected and analyzed, subsequently transformed into numerical values to calculate percentages and made graphs, and in this way determine whether the use of simulators as a teaching tool was a strategy that improved the teaching-learning of the law of conservation of matter and helps students to understand the relationship and importance of this law in chemical reactions.

The assessment instrument (Appendix 1) consisted of twenty multiple-choice questions that were selected based on the agenda (Unit 3: Chemical Equations). It was divided into five topics with four questions.

- Law on the Conservation of Matter (6, 8, 9, and 20)

- Chemical reaction and equation $(14,15,16$, and 17$)$

- Symbol recognition in the representation of a chemical equation $(10,11,12$, and 13$)$

- Oxidation status $(4,5,7$, and 19$)$

- Balancing chemical equations (1,2,3, and 18).

To evaluate the learning's acquired by students, the results were compared and standardized using the Hake (1998) equation where $\mathrm{g}$, is the relationship between the results of $\%$ of correct answers after the test and before the test:

$$
\mathrm{g}=\frac{\text { postest } \%-\text { pretest } \%}{100 \%-\text { pretest } \%}
$$

Based on the results obtained from the initial application of the evaluation instrument, the study guides were designed to help students review the topics in Unit 3. Appendix 2: Law on the Conservation of Matter https://drive.google.com/file/d/1w DQpZjXrqUXblVEIzspTxLliXNyXpxcG/view?usp=sharing. Appendix 3: Practice of Learning 1: https://drive.google. com/file/d/1Ok-ftN8-kzGfddCN2PN7j3AUO5LN4Vwy/ view?usp=sharing. Appendix 4: Relationship of the Law of Conservation of Matter to Chemical Reactions: https:// drive.google.com/file/d/13kiIK1Y4hs1SzCdrSYAyDxk z0N6ftmeW/view?usp=sharing. Appendix 5: Practice of Learning $2 \mathrm{https}$ ://drive.google.com/file/d/1x8JGg2uWcV f2p7KtQc1P2U0EtPtCcx/view?usp=sharing).

As part of the didactic strategy, online simulators were used for teaching-learning the Law of Conservation of Matter and its relationship with chemical reactions. It is important to mention that during the use of simulators students were encouraged with a positive and participatory attitude by the new teaching strategy they were going to experience, since it was the $1^{\text {st }}$ time that a non-traditional teaching model supported by ICT was implemented in school.

PhET simulators are freely accessible that can be used in schools that do not have a school chemistry laboratory and allow the student to understand abstract and complex topics through visualization and interaction in non-traditional learning environments, facilitating autonomous and self-taught learning. One of them is: https://phet.colorado.edu/sims/html/reactantsproducts-and-leftovers/latest/reactants-products-and-leftovers es.html. In this simulator, the student reinforces the concept of Law of Conservation of Matter, by performing different types of reactions, where the student has to create a specific type of reaction based on the chemical equation posed. The student will need to be able to reinforce the concepts of reagents, products, and understand the difference between reaction and chemical equation. They can then practice with hypothetical reactions all the knowledge acquired during this process. Another is: https:// phet.colorado.edu/sims/html/balancing-chemical-equations/ latest/balancing-chemical-equations_es.html. In this simulator the student needs to be able to reinforce the relationship that exists between the Law of Conservation of Matter and chemical reactions, identifying in the first instance the reagents and products of the given equation and based on this information decide which stoichiometric coefficients must be modified to be able to balance the equation thus complying with the Law of Conservation of the Matter. Throughout this process, the student has the opportunity to see graphically in the simulator what occurs when the stoichiometric coefficient is modified in one specific compound or element. This should lead to meaningful learning which will lay the foundation for understanding more complex topics.

Students must perform the following procedure for the simulation:

1. Go to the Google search engine

2. Write in the search engine: simulator in PhET chemistry

3. Click on: Chemistry - PhET Simulations (see Figure 3). 
Search and select: Reagents, products, and surpluses.

Download (see Figures 4 and 5).

Find and select: Balancing chemical equations.

Download (see Figures 6 and 7).

Once the download is done, students will start with level 1. (There are three levels ranging from simple to complex, see Figure 8).

\section{RESULTS AND DISCUSSION}

The results are presented and analyzed using bar charts, allowing to visualize the progress that students achieved using ICT. To perform the analysis of the results by question obtained from the application of the evaluation instrument such as pre-test and post-test (Appendix 1) it was counted how many students correctly responded to each of the questions presented in the evaluation instrument. As shown in Figure 9, the teaching strategy used for the teaching-learning of the Law on the Conservation of Matter and its relationship to chemical reactions showed a positive impact on all the questions included in the test, being question 6 (law on the conservation of matter) that achieved the greatest $\%$ increase in academic performance after the use of simulators, this shows that the use of ICT in education are a key tool for the teaching-learning process, facilitating the understanding of abstract and complex information, resulting in meaningful learning in students.

The results obtained are shown in Table 1, which details the $\%$ increase in assertiveness academic performance obtained by students in each of the topics included.

The topic 5 (balance of chemical equations) was the one that obtained the least \% increase, this tells us that these students still hold difficulties in the appropriation of this concept; however, the didactic strategy applied in this work, established the basis to facilitate students the understanding of more complex topics such as the balancing of equations (see Figure 10).

To evaluate the learning difference between pre-test and posttest, Hake's standardized gain Figure 11 was determined. This factor is reported as a number between zero and one. It can be observed that $g$ has values for categories 2, 3, 4, and 5 included

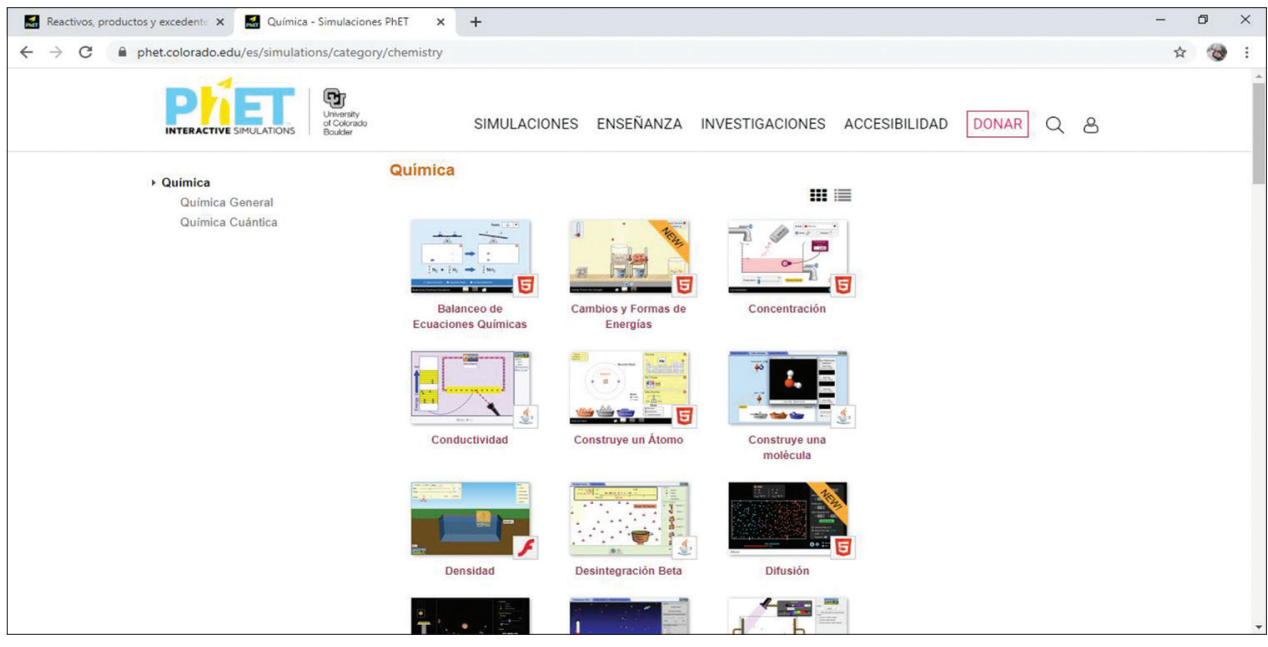

Figure 3: Chemistry- PhET Simulations

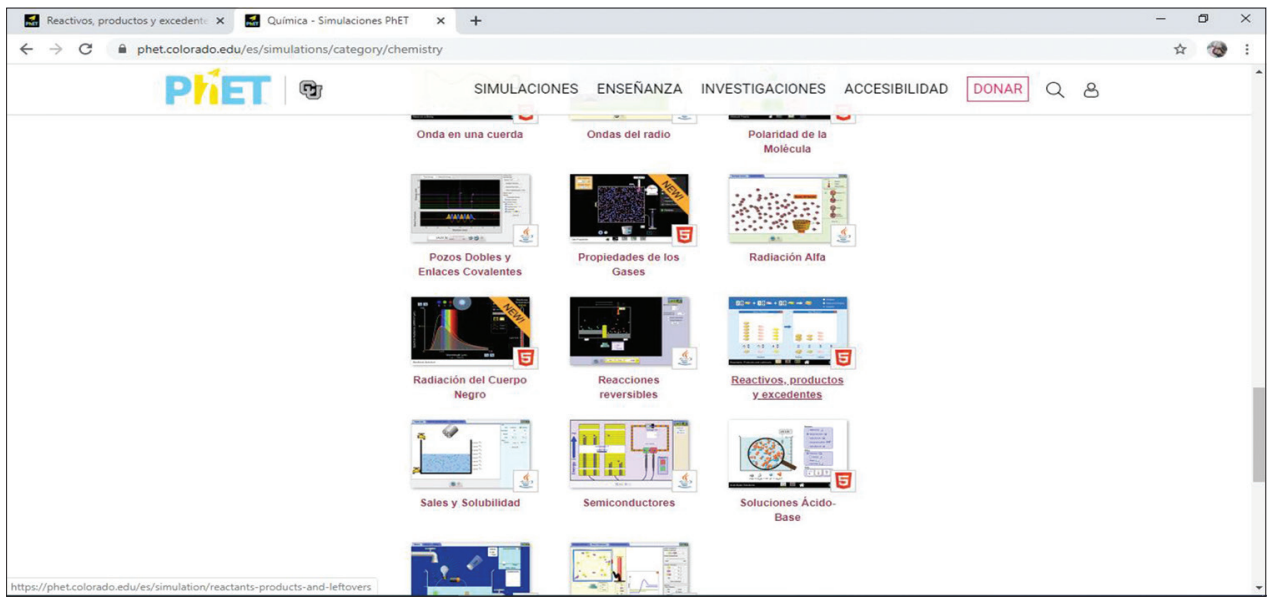

Figure 4: Selecting the PhET Simulator: Reagents, Products and Surpluses 


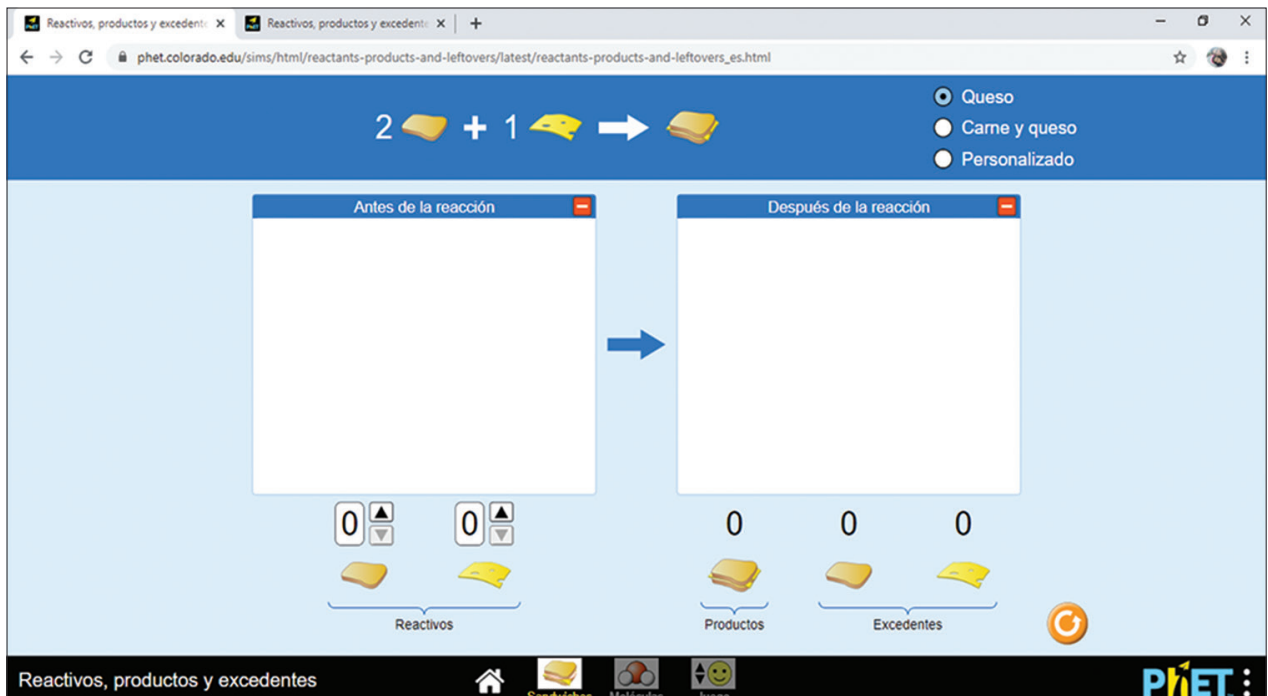

Figure 5: PhET Simulator: Reagents, Products and Surpluses

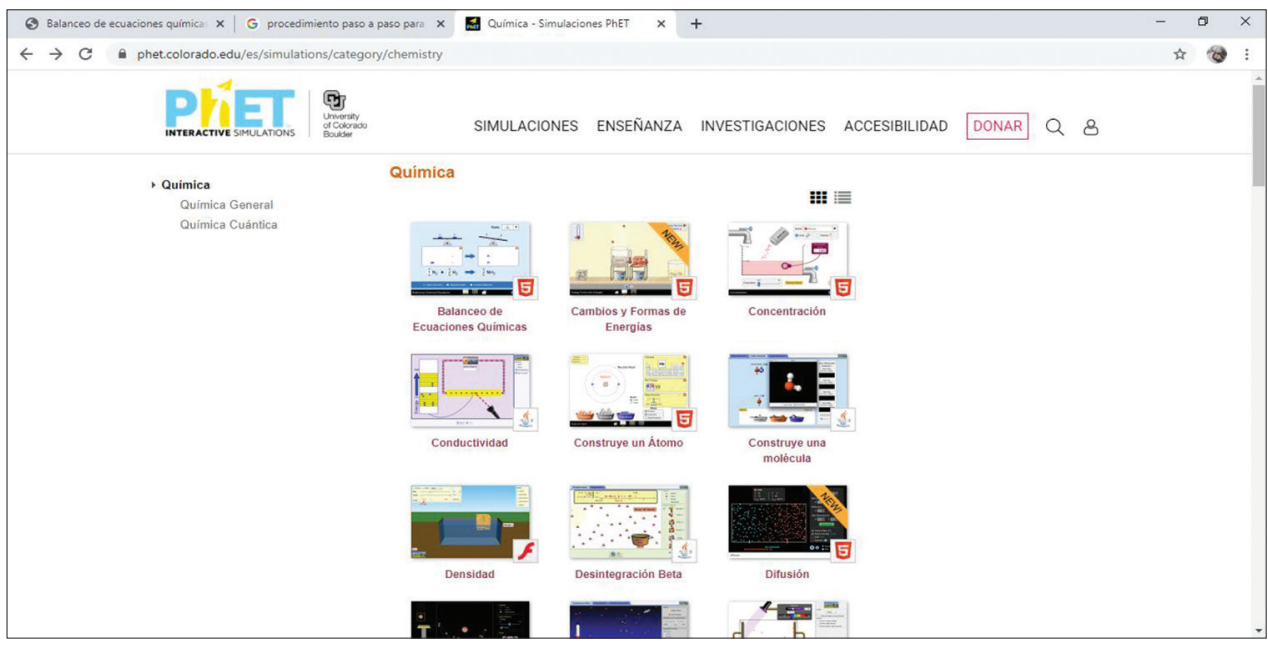

Figure 6: Chemistry- PhET Simulations

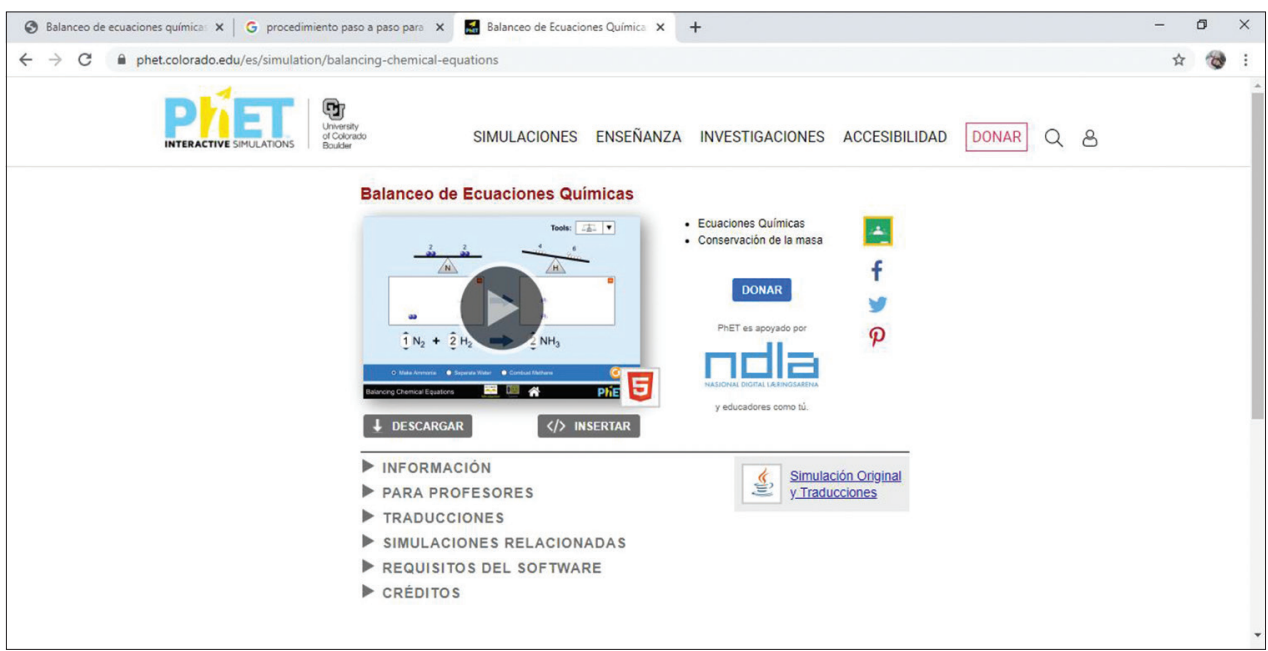

Figure 7: Selecting the PhET Simulator: Balancing Chemical Equations 


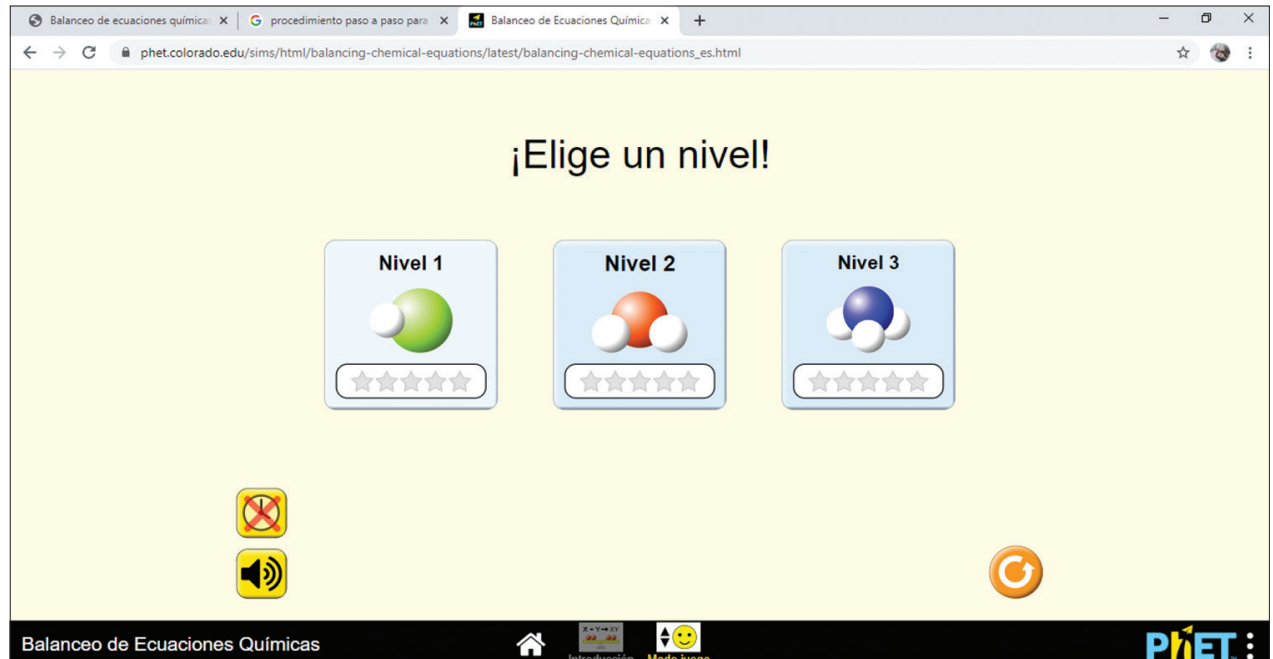

Figure 8: PhET Simulator: Balancing Chemical Equations

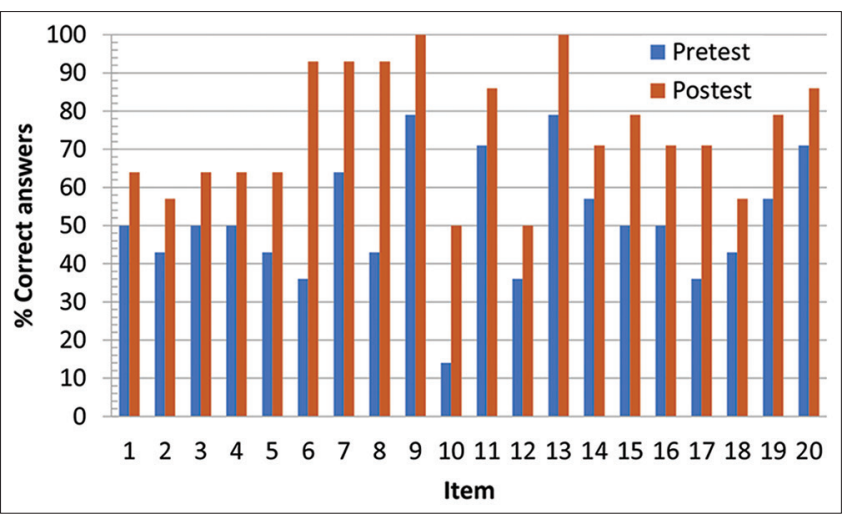

Figure 9: Pretest and posttest results by item

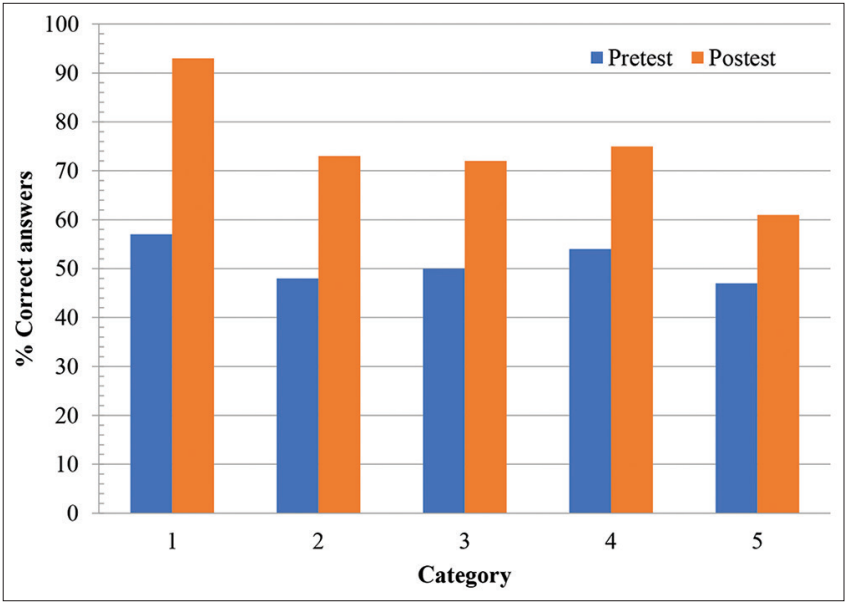

Figure 10: Pretest and posttest results applied to each topic

in the test, with an average of $\mathrm{g} \times 0.44$, for category 1 (Law on the Conservation of Matter) you have an average value of $g \times 0.82$ with a range of values, the results of which are characteristic of active learning achieved from the application of the teaching strategy $(0.2 \leq \mathrm{g} \leq 0.6) \mathrm{g}>0.8-10$.

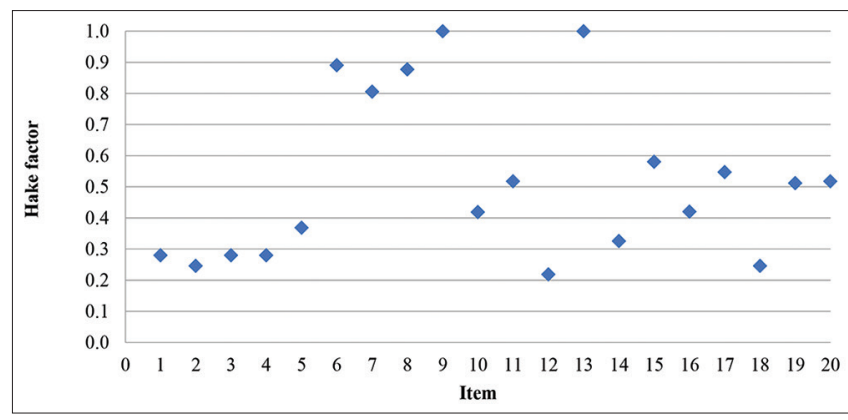

Figure 11: Hake Factor vs Item

Table 1: Increased assertiveness in the topics included in the test

\begin{tabular}{lccc}
\hline Topic & $\begin{array}{c}\text { \% Initial } \\
\text { assertiveness }\end{array}$ & $\begin{array}{c}\text { \% Final } \\
\text { assertiveness }\end{array}$ & \% Increase \\
\hline 1 & 57 & 93 & 36 \\
2 & 48 & 73 & 25 \\
3 & 50 & 72 & 22 \\
4 & 54 & 75 & 21 \\
5 & 47 & 61 & 14 \\
\hline
\end{tabular}

\section{CONCLUSION}

After applying the teaching strategy of online simulators for the teaching-learning of the Law of Conservation of Matter and its relationship to chemical reactions in higher middle education, it was observed that the use of simulators as part of the teaching strategy yielded satisfactory results, since in each of the categories in which the test was classified a \% increase in the assertiveness academic performance of the students at the time of answering the evaluation tool. Demonstrating greater appropriation of knowledge and meaningful learning in them.

The topic 1 (Law on the Conservation of the Matter) was the one that had the greatest impact on the $\%$ increase in assertiveness (36\%) and in Hake's standardized gain, indicating 
that there was active participation of students in making use of simulators, that is, because using them as a teaching tool and complementary to the form of teaching-learning used in class, it allows students to improve the understanding of concepts difficult or impossible to observe with the naked eye even in school laboratories. In addition to the observed in the students a positive and participatory attitude generated by the motivation to experience for the $1^{\text {st }}$ time a model of nontraditional teaching $\mathrm{g}>0.8-1.0$ ).

The interaction that the simulator allows, helps them to visually understand what happens during a chemical reaction, because it is important to verify that the Law of Conservation of Matter is complied with, which indicate the symbols in a chemical equation, because it is important to identify the oxidation status of the elements involved in a reaction and finally how to apply all this knowledge for the balancing of chemical equations, resulting in a significant improvement in the school performance of the students.

The use of ICT as a teaching strategy allowed me as a teacher to explain abstract and complex concepts that for students were difficult to understand and visualize, especially since this school does not have the necessary infrastructure to have a school laboratory, which allows students to visualize the knowledge learned in a real context, however, through these tools they were able to achieve meaningful learning that was reflected in their academic performance.

In this new age that is living in education it is important that as teachers, we use innovative and different teaching strategies in the classroom, a good option is the use of ICTs, which allow us to capture students' interest in subjects that they consider difficult, boring and in no practical from means that they know and master perfectly, as is the use of computer and technological tools.

\section{REFERENCES}

Brown, T., LeMay, E., and Bursten, B. (1998). Chemistry Central Science. United Kingdom: Pearson.

Chang, R. (2010). Chemistry. United States: McGraw Hill.

Chiu, M., \& Wu, H. (2009). The Roles of Multimedia in the Teaching and Learning of the Triplet Relationship in Chemistry. Berlin, Germany: Springer.

Galagovsky, R. (2007). Teaching chemistry vs learning chemistry. An equation that is not balanced. Viva Chemical Magazine, 6, 1-13.

Giammatteo, L., \& Obaya, A. (2018). Assessing chemistry laboratory skills through a competency-based approach in high school chemistry course. Science Education International, 29(2), 103-109.

Hake, R. (1998). Interactive-engagement versus traditional methods: A six thousand-student survey of mechanics test data for introductory physics courses. American Journal of Physics, 66, 1-27.

Hernández, B.P., Obaya, A.V., Montaño, O.C., \& Vargas-Rodríguez, Y.M. (2020). Didactic strategy: Interactive digital board in teaching learning heat capacity for high school. International Journal of Science and Research, 9(10), 216-223.

Mistler-Jackson, M., \& Butler-Songer, N. (2000). Student motivation and internet technology: Are students empowered to learn science? Journal of Research in Science Teaching, 37(5), 459-479.

Mumtaz, S. (2000). Factors affecting teachers' use of information and communication technology: A review of the literature. Journal of Information Technology for Teacher Education, 9(3), 319-342.

Perez-Rivero, M., Obaya, A., Giamatteo, L., Montaño-Osorio, C., \& Vargas-Rodríguez, Y.M. (2019). Didactic strategy for learning and teaching of functional groups in high school chemistry. Science Education International, 30(2), 85-91.

Webb, M. (2005). Affordances of ICT in science learning: Implications for an integrated pedagogy. International Journal of Science Education, 27(6), 705-735.

Webb, M., \& Cox, M.A. (2004). Review of pedagogy related to information and communication technology. Technology, Pedagogy and Education, 13(3), 235-282. 


\section{APPENDIX}

Appendix 1: Evaluation instrument (Pre-test and Post-test)

Instructions: The following questions present four solution alternatives, underline the one you consider correct. If any of the problems require any development, it can be done next to the question in question.

Answer questions 1 through 3 based on the following information:

The oxidized and reduced terms are defined based on the gain or loss of electrons a substance suffers during a chemical reaction. In the following chemical reaction

$$
\mathrm{Cr}+\mathrm{O}_{2} \rightarrow \mathrm{Cr}_{2} \mathrm{O}_{3}
$$

1. The compound that behaves as an oxidizing agent is:
A. $\mathrm{Cr}$
B. $\mathrm{O}_{2}$
C. $\mathrm{Cr}_{2} \mathrm{O}_{3}$
D. None of the above

2. The compound that behaves as a reducing agent is:
A. $\mathrm{Cr}$
B. $\mathrm{O}_{2}$
C. $\mathrm{Cr}_{2} \mathrm{O}_{3}$
D. None of the above

3. The coefficients that balance the above equation are:
A. $3,4,2$
B. $2,3,4$
C. $4,3,2$
D. $2,4,3$

4. Redox reactions occur when substances that are combined exchange electrons. Simultaneously, with this exchange, a variation in the number of oxidation (oxidation state) of the reacting chemical species takes place. Based on the above, determine the oxidation status of the elements in calcium sulfate: $\left(\mathrm{CaSO}_{4}\right)$ :
A. $\mathrm{Ca}^{+2} \mathrm{~S}^{+5} \mathrm{O}^{-2}$
B. $\mathrm{Ca}^{+2} \mathrm{~S}^{+6} \mathrm{O}^{-2}$
C. $\mathrm{Ca}^{+1} \mathrm{~S}^{+6} \mathrm{O}^{-1}$
D. $\mathrm{Ca}^{+2} \mathrm{~S}^{+4} \mathrm{O}^{-1 / 2}$

5. The oxidation number or state is defined as:

A. The number above that represents the charge of the atom

B. Electron gain that is carried out in an oxide-reduction process

C. Electron loss that takes place in an oxide-reduction process.

D. The load we assign to atoms in a molecule or ion, based on the assumption that all the bonds present in it are $100 \%$ ion.

6. According to the equation represented, it is valid to state that:

\begin{tabular}{lc}
\multicolumn{2}{c}{$2 \mathrm{H}_{2(g)}+\mathrm{O}_{2(g)} \rightarrow 2 \mathrm{H}_{2} \mathrm{O}_{(l)}$} \\
\hline Element & Molar mass (g/mol) \\
\hline $\mathrm{H}$ & 1 \\
$\mathrm{O}$ & 16 \\
$\mathrm{H}_{2} \mathrm{O}$ & 18 \\
\hline
\end{tabular}
A. The amount of matter was preserved
B. The number of moles was preserved
C. Increased the number of molecules
D. Increased the number of atoms in each element 
7. Barium nitrate $\mathrm{Ba}\left(\mathrm{NO}_{3}\right)_{2}$ is used in the production of flares and in artificial fires to make a green color. The oxidation states of the elements present in this compound are respectively:
A. $-2,+1,+6$
B. $+5,+2,-1$
C. $-1,+5,-2$
D. $+2,+51,-2$

8. Determine whether the following equation complies with the law on the conservation of matter:

$$
\mathrm{CH}_{4(g)}+2 \mathrm{O}_{2(g)} \rightarrow \mathrm{CO}_{2(g)}+2 \mathrm{H}_{2} \mathrm{O}_{(g)}
$$

\begin{tabular}{lc}
\hline Element & Molar mass $(\mathbf{g} / \mathbf{m o l})$ \\
\hline $\mathrm{CH}_{4}$ & 16 \\
$\mathrm{O}_{2}$ & 32 \\
$\mathrm{CO}_{2}$ & 44 \\
$\mathrm{H}_{2} \mathrm{O}$ & 18 \\
\hline
\end{tabular}

A. No, because of the number of atoms of each type in reactive particles is greater than the number of atoms of each type in the products

B. Yes, because the mass of the products is greater than the mass of the reagents

C. Yes, because the number of substances that react is equal to the number of substances obtained

D. Yes, because the total mass of the reagents is equal to the total mass of the products

9. In 1774, Lavoiser denounced: "Matter is not created or destroyed, it is only transformed." Based on the information above, select the image that best represents it.

A.

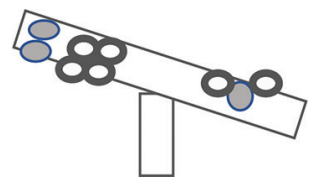

B.

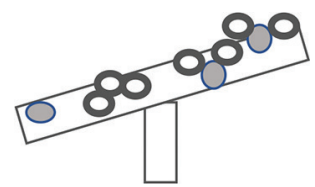

C.

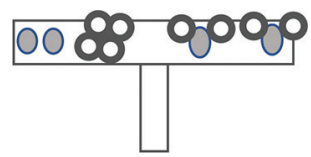

10. Urea is a crystalline, colorless chemical compound of formula $\mathrm{CO}\left(\mathrm{NH}_{2}\right)_{2}$ found abundantly in urine and fecal matter. It is the main terminal product of protein metabolism in humans and other mammals. According to the above chemical formula it is valid to state that this:
A. It has an atom of $\mathrm{N}$
B. It has $4 \mathrm{H}$ molecules
C. It consists of four different elements
D. It has an oxygen atom

\section{Answer questions 11 through 13 based on the following information:}

Plants use a chemical reaction called photosynthesis to convert carbon dioxide and water into food (glucose) and oxygen. This is undoubtedly one of the most common and one of the most important chemical reactions, because in this way plants can produce their own food, besides that it is the process by which they convert carbon dioxide into oxygen. Oxygen is a fundamental substance for life, as it is necessary for breathing not only lung but also cellular, of organisms.

The reaction of photosynthesis is as follows:

$$
\left.\left.\mathrm{CO}_{2(g)}\right)+12 \mathrm{H}_{2} \mathrm{O}_{()} \rightarrow \mathrm{C}_{6} \mathrm{H}_{12} \mathrm{O}_{6(s)}+6 \mathrm{O}_{2(g)}\right)+6 \mathrm{H}_{2} \mathrm{O}_{(g)}
$$

According to the symbols found in the above equation: 
11. The arrow represents $\rightarrow$ :
A. Moles
B. Heat
C. Change
D. Reversible

12. How many moles of $\mathrm{CO}_{2(g)}$ and $\mathrm{H}_{2} \mathrm{O}_{(\mathrm{l})}$ are required to produce a mol of $\mathrm{C}_{6} \mathrm{H}_{12} \mathrm{O}_{6(s)}$ :
A. 12 moles de $\mathrm{CO}_{2(g)}$ and 6 moles de $\mathrm{H}_{2} \mathrm{O}_{(l)}$
B. 6 moles de $\mathrm{CO}_{2(g)}$ and 24 moles de $\mathrm{H}_{2} \mathrm{O}_{(l)}$
C. 6 moles de $\mathrm{CO}_{2(g)}$ and 12 moles de $\mathrm{H}_{2} \mathrm{O}_{(())}$
D. 1 moles de $\mathrm{CO}_{2(g)}$ and 1 moles $\operatorname{de} \mathrm{H}_{2} \mathrm{O}_{(l)}$

13. Symbols in parentheses (s), (g) y (l), represent:
A. State of matter in which each compound is located
B. Moles
C. Energy
D. Heat

14. The following boxes represent the reaction between the elemental substance $\mathrm{X}(\bigcirc)$ ) with the elemental substance $\mathrm{Y}$ ( based on this information answers the following questions:

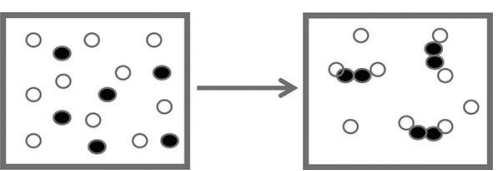

The boxes on the left and right represent, respectively:
A. Elements and products
B. Homogeneous and heterogeneous mixture
C. Reagents and molecules
D. Reagents and products

15. Which of the following equations best describes the reaction?
A. $X+Y \rightarrow X Y$
B. $2 X+2 Y \rightarrow X_{2} Y_{2}$
C. $X+2 Y \rightarrow X Y_{2}$
D. $2 X+Y \rightarrow X_{2} Y$

16. The process in which substances come together to transform into different ones is called:
A. Chemical reaction
B. Homogeneous mixing
C. Chemical equation
D. Heterogeneous mix

17. One of the most well-known acid-base reactions is that which occurs between hydrochloric acid and the physical soda that gives the formation of table salt $(\mathrm{NaCl})$. The equation that describes this process is:
A. $\mathrm{HCl}+\mathrm{KOH} \rightarrow \mathrm{KCl}+\mathrm{H}_{2} \mathrm{O}$
B. $2 \mathrm{HCl}+\mathrm{NaOH} \rightarrow \mathrm{NaCl}+\mathrm{H}_{2} \mathrm{O}$
C. $\mathrm{HCl}+2 \mathrm{NaOH} \rightarrow \mathrm{NaCl}+\mathrm{H}_{2} \mathrm{O}$
D. $\mathrm{HCl}+\mathrm{NaOH} \rightarrow \mathrm{NaCl}+\mathrm{H}_{2} \mathrm{O}$

18. The correctly balanced equation is:
A. $\mathrm{NaOH}+\mathrm{H}_{2} \mathrm{SO}_{4} \rightarrow \mathrm{Na}_{2} \mathrm{SO}_{4}+\mathrm{H}_{2} \mathrm{O}$
B. $\mathrm{NaOH}+2 \mathrm{H}_{2} \mathrm{SO}_{4} \rightarrow \mathrm{Na}_{2} \mathrm{SO}_{4}+\mathrm{H}_{2} \mathrm{O}$
C. $2 \mathrm{NaOH}+\mathrm{H}_{2} \mathrm{SO}_{4} \rightarrow \mathrm{Na}_{2} \mathrm{SO}_{4}+2 \mathrm{H}_{2} \mathrm{O}$
D. $2 \mathrm{NaOH}+2 \mathrm{H}_{2} \mathrm{SO}_{4} \rightarrow 2 \mathrm{Na}_{2} \mathrm{SO}_{4}+2 \mathrm{H}_{2} \mathrm{O}$

19. Ammonia $\left(\mathrm{NH}_{3}\right)$ it is a gas that dissolved in water can be used in countless cases, especially as a household cleaner. Its properties make it a very suitable product to remove dirt and stains from numerous surfaces. The nitrogen and hydrogen oxidation numbers in this compound are:
A. $+3,-1$
B. $-3,-1$ 
C. $-3,+1$

20. The equation that complies with the law of conservation of matter and correctly represents the reaction presented in the following image is:

$+$

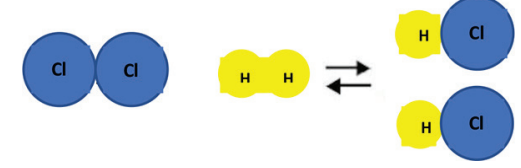
A. $\mathrm{Cl}_{2}+\mathrm{H}_{2} \rightarrow 2 \mathrm{HCl}$
B. $\mathrm{Cl}_{2}+\mathrm{H}_{2} \rightarrow \mathrm{HCl}$
C. $2 \mathrm{Cl}_{2}+2 \mathrm{H}_{2} \rightarrow 2 \mathrm{HCl}$
D. $\mathrm{Cl}_{2}+\mathrm{H}_{2} \rightarrow 1 / 2 \mathrm{HCl}$

Appendix 2: Law on the Conservation of Matter

https://drive.google.com/file/d/1gRKkGsAVBcF_gKTs1NFHRURhVatQKg5y/view?usp=sharing

Appendix 3: Practice of Learning 1

https://drive.google.com/file/d/1UdmagapcXtTk8D-tfVVscToHwXvLtraU/view?usp=sharing

Appendix 4: Relationship of the Law of Conservation of Matter to Chemical Reactions

https://drive.google.com/file/d/170VvEz35yY2hDB2Q3duBOurXGG4Bv1SM/view?usp=sharing

Appendix 5: Practice of Learning 2

https://drive.google.com/file/d/1WIvPrvUzTngVahm6c_4eT51ga0gHTVXr/view?usp=sharing 